\title{
Artificial Neural Networks Applied to Plant Disease
}

\author{
Nathalia H. Leite*, Fernando A. C. Gomide, Waldir C. de Jesus Junior
}

\begin{abstract}
An Artificial Neural Network (ANN) is an approximate mathematical model that attempts to mirror biological neural network in its structure and functionalities. ANNs are useful for many engineering tasks such as optimization, prediction, function approximation, pattern recognition, and control. In this reseach an ANN was used to approximate a function that relates the Leaf Area Index (LAl) with the Leaf Area Duration (LAD). The objective was to predict how LAD effects the development of Asian Soybean Rust (ASR) and to evaluate the temporal dynamics of this disease.
\end{abstract}

\section{Key words:}

Artificial neural networks, asian soybean rust, non-linear modeling.

\section{Introduction}

ANNs are particularly useful when no effective analytical approach exists to model non-linear systems dependencies, but representative input-output data are available. The fact that ANNs can approximate non-linear dependencies and process complex data makes them ideal for modeling of agricultural phenomena and processing agricultural data (Jha, 2016).

The main objective of this research was to compare the performance of ANNs, Image 1, and classical regression methods to study ASR. Three statistical tools were utilized: Microsoft Excel, R-Studio, and SAS/Minitab. The goal, for all of them, was to approximate a function that relates LAI and LAD. LAI is the one-sided area of leaf tissue per unit ground area (leaf area/ground area). LAD is the maintenance period of the leaf area during the vegetative cycle.

\section{Results and Discussion}

The data were obtained from Moreira (2013) whose values are derived from experiments conducted in Lucas do Rio Verde - Mato Grosso, from 2009 to 2011. In Chart 1, there are data for Oct/2010 and three maturity groups: early, mid, and late.

A detailed analysis of Chart 1 shows that, on average, the SAS/Minitab function is capable of representing $85 \%$ of the experimental data. The value of this variable for Microsoft Excel and R-Studio is $90 \%$.
Image 1. Topology of the ANN.

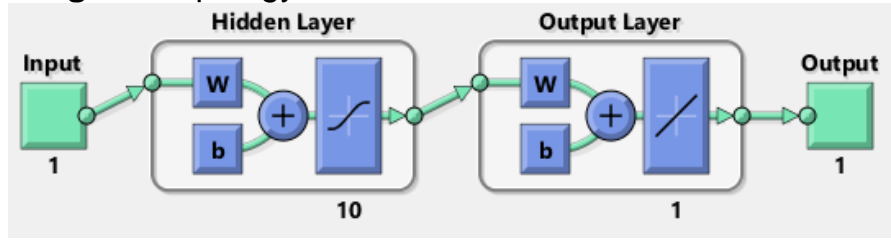

Chart 1. ANN x Microsoft Excel $\times$ R-Studio $\times$ SAS/Minitab.

\begin{tabular}{|c|c|c|c|}
\hline \multirow{2}{*}{ Maturation } & \multicolumn{3}{|c|}{$\mathrm{R}^{2}$ Value } \\
\cline { 2 - 4 } & ANN & $\begin{array}{c}\text { Microsoft } \\
\text { Excel/R- } \\
\text { Studio }\end{array}$ & SAS/Minitab \\
\hline \multicolumn{4}{|c|}{ Oct/2010 } \\
\hline Early & 0.97303 & 0.86510 & 0.84100 \\
\hline Mid & 0.96935 & 0.93000 & 0.82200 \\
\hline Late & 0.97639 & 0.91500 & 0.89100 \\
\hline
\end{tabular}

\section{Conclusions}

The tests carried out with the other months, in general, had similar behavior, positioning ANN in the first place in relation to performance. The good results of the ANN can be explained by its great ability to detect non-linear relationships among variables of a model, being widely applied to plant disease problems.

\section{Acknowledgement}

This research is being supported by São Paulo Research Foundation (FAPESP), since March of 2016, under grant \#2015/19698-3.

Jha, G. K. (2016). "Artificial neural networks and its applications". Available at http://www.iasri.res.in/ebook/ebadat/5-Modeling\%20and\%20Forecasting\%20 Techniques\%20in\%20Agriculture/5-ANN_GKJHA_2007.pdf. Accessed in 04/2016.

Moreira, E. N. (2013). "Comparative epidemiology of Asian soybean rust" (in

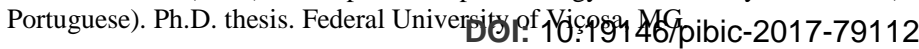
XXV Congresso de Iniciação Científica da UNICAMP 